\title{
THE ATMOSPHERE BELOW 200 KM OVER NORILSK AT SOLAR MINIMUM AND MAXIMUM
}

\section{O.E. Yakovleva}

Institute of Solar-Terrestrial Physics SB RAS,

Irkutsk, Russia, yakovleva@iszf.irk.ru

\section{G.P. Kushnarenko}

Institute of Solar-Terrestrial Physics SB RAS,

Irkutsk,Russia,kusch@iszf.irk.ru

\author{
G.M. Kuznetsova \\ Institute of Solar-Terrestrial Physics SB RAS, \\ Irkutsk,Russia,kuz@iszf.irk.ru
}

\begin{abstract}
We have obtained seasonal variations in relative values of the main thermospheric gas components $[\mathrm{O}] /\left[\mathrm{N}_{2}\right]$ and $\left[\mathrm{O}_{2}\right] /[\mathrm{O}]$ during solar maximum. We have used our method and measurements made with the Norilsk digisonde $\left(69.4^{\circ} \mathrm{N}, 88.1^{\circ} \mathrm{E}\right)$ at heights of the ionospheric layer F1 (120-200 km) in quiet and disturbed geomagnetic conditions. We have compared $[\mathrm{O}] /[\mathrm{N} 2]$ and $[\mathrm{O} 2] /[\mathrm{O}]$ ratios during solar maximum with the corresponding values for the long period of solar minimum (2007-2009) in Norilsk. The relative
\end{abstract}

content of atomic oxygen particles has been found to increase during solar maximum by more than $35 \%$ in winter and autumn on quiet and disturbed days. In spring and summer, the atmosphere is enriched with molecular oxygen particles by $20 \%$ both on quiet and disturbed days of solar maximum as compared to the conditions of solar minimum.

Keywords: gas component ratios, geomagnetic disturbances.

\section{INTRODUCTION}

The problem of determining the neutral gas components of the thermosphere for different heliogeophysical conditions through ionospheric measurements is still relevant today. The use of regular measurements in our method, which are made by a vertical sounding method, enables us to monitor thermospheric conditions at a given time.

The gas composition at F1-region heights is characterized mainly by the ratio of oxygen atoms to oxygen and nitrogen molecules. The effect of the gas composition on $N_{\mathrm{e}}$ and $N(h)$ is most pronounced at heights below $200 \mathrm{~km}$, where the photochemical equilibrium condition holds usually during daylight hours. This allows us, through the use of the semi-empirical model (SEM) [Shchepkin et al., 1997], to describe the relation of $N_{\mathrm{e}}$ with the thermospheric gas composition, its temperature, and solar flux. From regular measurements and with the help SEM, we have obtained the ratios $[\mathrm{O}] /\left[\mathrm{N}_{2}\right]$ and $\left[\mathrm{O}_{2}\right] /[\mathrm{O}]$ at heights between 120 and 200 $\mathrm{km}$ during the long solar minimum in 2007-2009, using the well-known proprietary technique [Kushnarenko et al., 2011, 2014; Yakovleva et al., 2015]. Accumulation of necessary data from digisonde measurements at the station Norilsk allows us to make calculations for other solar activity conditions as well. Let us present our estimates of $[\mathrm{O}] /\left[\mathrm{N}_{2}\right]$ and $\left[\mathrm{O}_{2}\right] /[\mathrm{O}]$ at $120-200 \mathrm{~km}$ for solar maximum. The ratios were obtained for the daylight hours (7-18 LT) under different geomagnetic conditions. We compared them with the corresponding values for solar minimum.

\section{METHOD AND DATA}

The semi-empirical model is based on a regression equation:

$$
N_{\mathrm{e}} / N_{\mathrm{av}}=X_{1}+X_{2}\left[n_{1} /\left(5 n_{2}+n_{3}\right)\right]^{1.5}+
$$

$$
\begin{aligned}
& +X_{3}\left(n_{1} / n_{3}\right)^{0.5}(\cos \chi)^{0.5}+ \\
& +X_{4} \exp \left[-\left(T_{\mathrm{ex}}-600\right) / 600\right]+X_{5}\left(E / E_{0}\right) .
\end{aligned}
$$

Here, $N_{\mathrm{e}}$ is the electron density; $N_{\mathrm{av}}$ is the average value of $N_{\mathrm{e}}$ for the entire data set separately for each height; $X_{j}$ is the coefficients of the model equation; $n_{1}, n_{2}, n_{3}$ are concentrations of atomic oxygen and molecular oxygen and nitrogen respectively; $\chi$ is the solar zenith angle; $T_{\mathrm{ex}}$ is the exospheric temperature; $E_{0}$ is the energy of ionizing radiation $E$ at solar maximum. Equation (1) can be written as follows:

$$
\begin{aligned}
& N_{\mathrm{e}} / N_{\mathrm{av}}=X_{1}+X_{2} R \sqrt{R} W+ \\
& +X_{3} \sqrt{R}(\cos \chi)^{0.5}+ \\
& +X_{4} \exp \left[-\left(T_{\mathrm{ex}}-600\right) / 600\right]+ \\
& +X_{5}\left(E / E_{0}\right) .
\end{aligned}
$$

Here, $\quad R=[\mathrm{O}] /\left[\mathrm{N}_{2}\right] ; \quad W=\left[1 /\left(1+5 R_{2}\right)\right]^{1.5} ; \quad R_{2}=\left[\mathrm{O}_{2}\right] /\left[\mathrm{N}_{2}\right]$; $R_{2} / R=\left[\mathrm{O}_{2}\right] /[\mathrm{O}]$, where [O], $\left[\mathrm{O}_{2}\right]$ and $\left[\mathrm{N}_{2}\right]$ are concentrations of oxygen atoms and oxygen and nitrogen molecules respectively. In the calculations, we have used thermospheric models [Hedin, 1987; Picone et al., 2002] and a model [Tobiska, Eparvier, 1998] of determining ionizing radiation energy. We took $N_{\mathrm{e}}$ values from measurements made with the Norilsk digisonde at 120-200 $\mathrm{km}$ during daylight hours. From these $N_{\mathrm{e}}$ values, we calculated SEM coefficients for each of the heights and for each period of interest (minimum, maximum, and medium solar activity). As an example, we present Table 1 that lists the coefficients for solar minimum used in the calculations (Table 1).

In Table $1, R_{\text {corr }}$ is the correlation coefficients between calculated and experimental $N_{\mathrm{e}}$ arrays for this period (in the calculation procedure for SEM coefficients).

The calculated coefficients of the model for different 
Table 1

Coefficients of the semi-empirical model (SEM) for solar minimum

\begin{tabular}{|c|c|c|c|c|c|c|c|}
\hline height & $X_{1}$ & $X_{2}$ & $X_{3}$ & $X_{4}$ & $X_{5}$ & $R_{\text {corr }}$ & $N_{\text {av }}$ \\
\hline 120 & -0.1844 & -7.403 & 4.842 & 0.0000 & 0.9708 & 0.935 & 7.51 \\
\hline 130 & -0.4140 & -7.960 & 5.459 & 0.2335 & 0.9473 & 0.904 & 8.57 \\
\hline 140 & -0.3128 & -8.238 & 5.310 & 0.2341 & 0.7888 & 0.941 & 10.25 \\
\hline 150 & -0.3352 & -7.917 & 5.106 & 0.4142 & 0.7005 & 0.950 & 12.07 \\
\hline 160 & -0.3521 & -7.048 & 4.688 & 0.5798 & 0.7009 & 0.958 & 13.80 \\
\hline 170 & -0.3646 & -5.463 & 4.130 & 0.7145 & 0.7496 & 0.960 & 15.39 \\
\hline 180 & -0.3462 & -2.644 & 3.430 & 0.7984 & 0.7455 & 0.936 & 17.16 \\
\hline 190 & -0.3267 & 1.388 & 2.659 & 0.8516 & 0.7008 & 0.832 & 19.49 \\
\hline 200 & -0.3604 & 5.298 & 1.983 & 0.9051 & 0.7580 & 0.697 & 22.32 \\
\hline
\end{tabular}

periods allow us to say that there is a connection between the results we obtained from them and the height range 120-200 km. From Equation (2) and from this data, we can find $R, R_{2}, R_{2} / R$.

\section{RESULTS AND DISCUSSION}

The method we describe enables us to estimate the ratios of gas components $[\mathrm{O}] /\left[\mathrm{N}_{2}\right]$ and $\left[\mathrm{O}_{2}\right] /[\mathrm{O}]$ at $120-200$ $\mathrm{km}$ during daylight hours (7-18 LT). The calculations are based on data on the electron density at these heights, obtained from measurements with the Norilsk digisonde $\left(69.4^{\circ} \mathrm{N}, 88.1^{\circ} \mathrm{E}\right)$. For the study, we have selected days with quiet and disturbed geomagnetic conditions in all seasons of 2014 - a year of solar maximum. Disturbed days were considered those with the geomagnetic index $A_{\mathrm{p}}>10$. The $F 10.7, A_{\mathrm{p}}$, and $D s t$ indices were taken from the WDC-C2 database in Kyoto [http://wdc.kugi.kyotou.ac.jp]. For each day, we calculated average $[\mathrm{O}] /\left[\mathrm{N}_{2}\right]$ and $\left[\mathrm{O}_{2}\right] /[\mathrm{O}]$ for near-noon hours (10-14 LT) and found average values for each season, and then we determined the mean square deviation $\sigma$ for them.

The results are presented in Table 2. By comparison, we give here the estimated $[\mathrm{O}] /\left[\mathrm{N}_{2}\right]$ and $\left[\mathrm{O}_{2}\right] /[\mathrm{O}]$ for 2008 , one of the three years of long solar minimum.

The estimated ratios are shown more clearly in the Figure, based on data from Table 2.

\section{THE $[\mathrm{O}] /\left[\mathrm{N}_{2}\right]$ RATIO}

The $[\mathrm{O}] /\left[\mathrm{N}_{2}\right]$ ratio in all seasons of solar minimum shows a slight (6-12\%) decrease when passing from quiet to disturbed conditions. A reason perhaps is that weak geomagnetic disturbances were analyzed because the period of the last solar minimum exhibited unusually quiet geomagnetic conditions [Belov, Gaidash, 2009]. The $[\mathrm{O}] /\left[\mathrm{N}_{2}\right]$ ratio is maximum in winter and minimum in summer: a decrease from one season to the next one is $\sim 25 \%$ on both disturbed and quiet days in all the three years of solar minimum.

During solar maximum, as during solar minimum, $[\mathrm{O}] /\left[\mathrm{N}_{2}\right]$ is the highest in winter and the lowest in summer. At solar maximum during the transition from winter to summer and vice versa, $[\mathrm{O}] /\left[\mathrm{N}_{2}\right]$ changes, however, 2.7 times on both quiet and disturbed days, which is much greater than that at solar minimum. The reason is

Table 2

Average $[\mathrm{O}] /\left[\mathrm{N}_{2}\right]$ and $\left[\mathrm{O}_{2}\right] /[\mathrm{O}]$ at solar maximum and minimum (Norilsk)

\begin{tabular}{|c|c|c|c|c|c|c|c|c|c|c|}
\hline \multirow{2}{*}{ Year } & \multirow{2}{*}{$F 10.7$} & \multicolumn{2}{|c|}{ winter } & \multicolumn{2}{|c|}{ spring } & \multicolumn{2}{c|}{ summer } & \multicolumn{2}{c|}{ fall } \\
\cline { 3 - 10 } & & disturb. & quiet & disturb. & quiet & disturb. & quiet & disturb. & quiet \\
\hline 2008 & 69 & 0.223 & 0.231 & 0.180 & 0.190 & 0.168 & 0.179 & 0.189 & 0.215 \\
\hline $\begin{array}{c}\sigma, \\
2008\end{array}$ & & 0.035 & 0.029 & 0.013 & 0.012 & 0.016 & 0.019 & 0.021 & 0.022 \\
\hline 2014 & 146 & 0.467 & 0.496 & 0.193 & 0.274 & 0.162 & 0.178 & 0.370 & 0.490 \\
\hline$\sigma$, & & 0.083 & 0.121 & 0.029 & 0.090 & 0.033 & 0.041 & 0.109 & 0.153 \\
2014 & & & & & & & & & \\
\hline & & & & & & & & & & \\
\hline 2008 & 69 & 0.630 & 0.590 & 0.541 & 0.495 & 0.512 & 0.468 & 0.450 & 0.432 \\
\hline$\sigma$, & & 0.111 & 0.094 & 0.028 & 0.025 & 0.050 & 0.039 & 0.051 & 0.057 \\
2008 & & & & & & & & & \\
\hline 2014 & 146 & 0.456 & 0.379 & 0.637 & 0.534 & 0.678 & 0.536 & 0.397 & 0.288 \\
\hline$\sigma$, & & 0.103 & 0.109 & 0.071 & 0.079 & 0.217 & 0.204 & 0.179 & 0.119 \\
2014 & & & & & & & & & \\
\hline
\end{tabular}



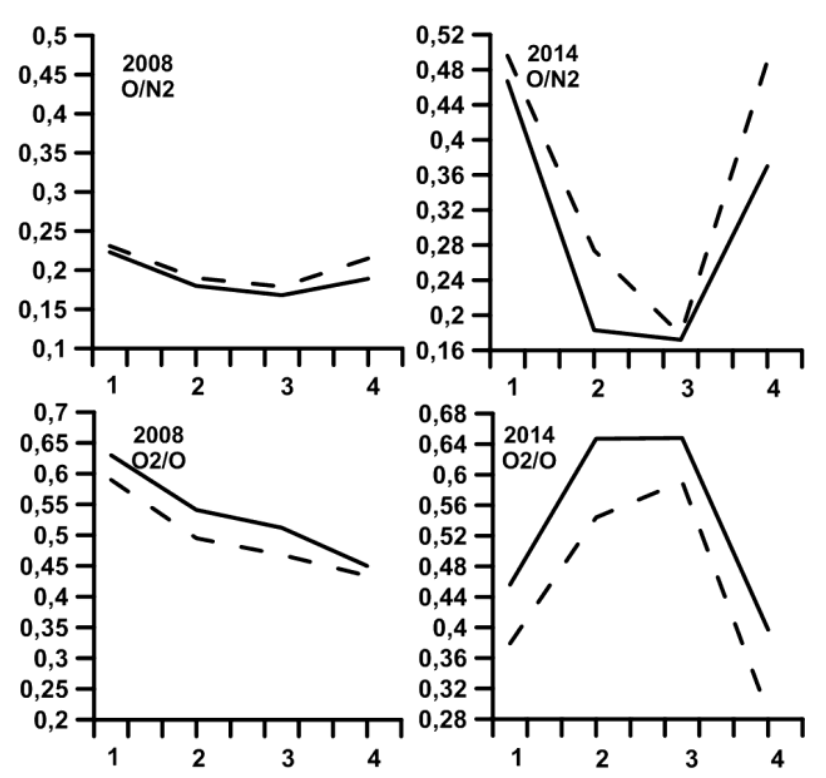

Average $[\mathrm{O}] /\left[\mathrm{N}_{2}\right]$ and $\left[\mathrm{O}_{2}\right] /[\mathrm{O}]$ at solar minimum (left panel, 2008) and maximum (right panel, 2014). Dashed curves show variations under quiet conditions

presumably the abnormally low level of solar EUV radiation in the last minimum: measurements have shown an energy reduction by $15 \%$ as compared to the previous two solar minima [Solomon et al., 2010]. Since the solar EUV radiation controls temperature and density of the thermosphere, during minimum of the last solar cycle the thermosphere was unusually cold, and the ionosphere was lower and cooler than that under the same conditions in the past, as confirmed by satellite measurements [Emmert et al,. 2010].

Comparison between quiet and disturbed geomagnetic conditions at solar maximum shows that in winter and summer $[\mathrm{O}] /\left[\mathrm{N}_{2}\right]$ changes little (3-6\%), whereas in spring and fall it can change by 35 and $25 \%$ respectively. This may be due to the more disturbed geomagnetic conditions during equinoctial periods. The $[\mathrm{O}] /\left[\mathrm{N}_{2}\right]$ ratio in spring increases by $25 \%$ on geomagnetically quiet days, but remains almost unchanged on disturbed days, as in summer. A significant increase in $[\mathrm{O}] /\left[\mathrm{N}_{2}\right]$ occurs in fall: by $56 \%$ on quiet days and by $50 \%$ on disturbed days. In winter, the increase is $\sim 50 \%$ under both quiet and disturbed conditions.

\section{THE $\left[\mathrm{O}_{2}\right] /[\mathrm{O}]$ RATIO}

During solar minimum, the highest $\left[\mathrm{O}_{2}\right] /[\mathrm{O}]$ is in winter under both quiet and disturbed conditions; the lowest, in fall. During solar maximum, the highest $\left[\mathrm{O}_{2}\right] /[\mathrm{O}]$ is in summer and spring; the lowest, in fall. As compared to quiet days, $\left[\mathrm{O}_{2}\right] /[\mathrm{O}]$ increases during geomagnetic disturbances in all seasons at both solar max- imum and minimum, by $10 \%$ during solar minimum. During solar maximum, $\left[\mathrm{O}_{2}\right] /[\mathrm{O}]$ increases greater on disturbed days: by $17 \%$ in winter and spring, by $28 \%$ in fall, by $10 \%$ in summer. This is presumably due to more disturbed geomagnetic conditions during solar maximum.

Note that at solar maximum, as compared to its minimum, $\left[\mathrm{O}_{2}\right] /[\mathrm{O}]$ in winter under quiet and disturbed conditions, as well as on geomagnetically quiet days in fall may decrease by $35 \%$. Under quiet and disturbed conditions, $\left[\mathrm{O}_{2}\right] /[\mathrm{O}]$ increases to $15 \%$ in spring, to $20 \%$ in summer, as compared to solar minimum.

\section{COMPARISON OF THE ESTIMATED RATIOS}

\section{Comparison with model values}

Using a large bulk of data on $N_{\mathrm{e}}$, obtained from experimental material on vertical ionospheric sounding (Norilsk), we have calculated $[\mathrm{O}] /\left[\mathrm{N}_{2}\right]$ and $\left[\mathrm{O}_{2}\right] /[\mathrm{O}]$ for daylight hours (7-18 LT) for all available days (quiet and disturbed) from 2003 to 2013 [Kushnarenko et al., 2016]. We compared them with $[\mathrm{O}] /\left[\mathrm{N}_{2}\right]$ obtained by the MSIS model for several years.

As an example, we take the summer season for a year of solar minimum and present an element of Table 3 , which compares $r_{1}=\left([\mathrm{O}] /\left[\mathrm{N}_{2}\right]\right)_{\text {calc }} /\left([\mathrm{O}] /\left[\mathrm{N}_{2}\right]\right)_{\mathrm{MSIS}}$ for several summer days of 2007 [Kushnarenko et al., 2016].

In most cases, for quiet summer days there is relatively good agreement between MSIS values - the difference is within $\pm 10 \%$. For disturbed days, the difference may be as great as $\pm 10-20 \%$; and in some cases, even greater. These results are also true for other years involved in the comparison. We can conclude that the working model fairly well describes the thermosphere over Norilsk under geomagnetically quiet conditions in summer and not always correctly during geomagnetic disturbances, especially during severe ones.

\section{Comparison with experimental values from GUVI measurements}

Calculated $[\mathrm{O}] /\left[\mathrm{N}_{2}\right]$ values were compared with those obtained from maps based on GUVI UV spectrometer measurements [http://guvitimed.jhuapl.edu]. These maps provide global coverage of Earth's mesosphere and lower thermosphere $(60-180 \mathrm{~km})$ during the daylight hours. For solar minimum, our estimates of $[\mathrm{O}] /\left[\mathrm{N}_{2}\right]$ (Table 2) are reasonably comparable to GUVI ones for spring and summer seasons, which are $0.1-0.3$.

In fall and winter, this correspondence is observed only in some cases. It seems that the thermospheric models used in our method describe the gas composition

\begin{tabular}{|l|c|c|c|c|c|c|c|c|c|c|c|c|}
\multicolumn{10}{c|}{$r_{1}=\left([\mathrm{O}] /\left[\mathrm{N}_{2}\right]\right)_{\text {calc }} /\left([\mathrm{O}] /\left[\mathrm{N}_{2}\right]\right)_{\mathrm{MSIS}}$} \\
\hline days & \multicolumn{10}{c|}{2007 (summer days $)$} \\
\hline disturb. & 0.95 & 1.00 & 1.01 & 1.12 & 1.01 & 0.95 & 1.01 & 1.04 & 1.01 & 1.12 & 1.07 & 1.07 \\
\hline quiet & 1.01 & 1.06 & 0.99 & 1.00 & 1.07 & 0.98 & 0.95 & 1.09 & 1.08 & 1.04 & 1.01 & 1.10 \\
\hline
\end{tabular}


in the Norilsk region correctly not in all seasons. For solar maximum, the comparison is consistent with our estimates: GUVI values in spring and summer range from 0.2 to 0.3 . The GUVI fall values of 0.5 also correlate with our values of $[\mathrm{O}] /\left[\mathrm{N}_{2}\right]$ (Table 2).

\section{CONCLUSION}

1. During solar minimum in all seasons, $[\mathrm{O}] /\left[\mathrm{N}_{2}\right]$ decreases slightly (6-12\%) during the transition from geomagnetically quiet to disturbed conditions.

2. During solar minimum and maximum, $[\mathrm{O}] /\left[\mathrm{N}_{2}\right]$ is maximum in winter and minimum in summer. During solar maximum on both quiet and disturbed days, $[\mathrm{O}] /\left[\mathrm{N}_{2}\right]$ may change 2.7 times from one season to another, which is much greater than that during solar minimum.

3. During solar maximum, the transition from quiet to disturbed conditions in winter and summer exhibits a slight decrease $(3-6 \%)$ in $[\mathrm{O}] /\left[\mathrm{N}_{2}\right]$, whereas in spring and fall this decrease can be as large as $35 \%$ and $25 \%$ respectively.

4. During solar maximum, $\left[\mathrm{O}_{2}\right] /[\mathrm{O}]$ is the highest in summer and spring, the lowest in fall. During geomagnetic disturbances, $\left[\mathrm{O}_{2}\right] /[\mathrm{O}]$ increases in all seasons during both solar maximum and minimum. During solar minimum, this change is within $10 \%$ in all seasons; during solar maximum, the increase is more significant: by $17 \%$ in winter and spring, by $28 \%$ in fall, but in summer it is still within $10 \%$.

5. Seasonal variations in $[\mathrm{O}] /\left[\mathrm{N}_{2}\right]$ and $\left[\mathrm{O}_{2}\right] /[\mathrm{O}]$ at heights below $200 \mathrm{~km}$ during solar maximum as compared to solar minimum are as follows:

5.1. On quiet and disturbed days, $[\mathrm{O}] /\left[\mathrm{N}_{2}\right]$ increases by more than $50 \%$ in winter and fall and changes slightly in spring and summer.

5.2. The ratio $\left[\mathrm{O}_{2}\right] /[\mathrm{O}]$ in winter and fall decreases by $35 \%$, whereas in spring and summer it increases by $15-20 \%$ on both quiet and disturbed days.

6 . The use of experimental data on the electron density, obtained from results of the method of vertical ionospheric sounding over Norilsk, and quite reasonable agreement with GUVI data improve the reliability of the estimates discussed.

The work was performed with budgetary funding of Basic Research program II.16 (Project II.16.1.1 «Research into the influence of solar activity and processes in the lower atmosphere on thermodynamic characteristics of the atmosphere, World Ocean, and climate»). The results were obtained using the equipment of Center for Common Use «Angara» [http://ckp-rf.ru/ckp/3056].

\section{REFERENCES}

Belov A.V., Gaidash S.P. Anomalously low solar and geomagnetic activities in 2007. Geomagnetizm $i$ aeronomiya [Geomagnetism and Aeronomy]. 2009, vol. 49, no. 5, pp. 595-602. (In Russian).

Emmert J.T., Lean J.L., Picone J.M. Record low thermospheric density during the 2008 solar minimum. Geophys. Res. Lett. 2010, vol. 37, L12102. DOI: 10.1029/2010GL043671.

Hedin A.E. MSIS-86 thermospheric model. J. Geophys. Res. 1987, vol. 92, no. A5, pp. 4649-4662.
Kushnarenko G.P., Kuznetsova G.M., Kolpakova O.E. Estimations of ratios of dominant gas components during strong and moderate geomagnetic disturbances in periods of solar activity decay and minimum. Solnechno-zemnaya fizika [SolarTerrestrial Physics]. 2011, iss. 19, pp. 134-139. (In Russian).

Kushnarenko G.P., Yakovleva O.E., Kuznetsova G.M. Seasonal variations in ratios of main gas components of thermosphere in the solar activity last minimum (2007-2009). Solnechno-zemnaya fizika [Solar-Terrestrial Physics]. 2014, iss. 25, pp. 29-32. (In Russian).

Kushnarenko G.P., Yakovleva O.E., Kuznetsova G.M. Long-term variations in the neutral gas composition of the termosphere above Norilsk (2003-2013 гг.). Solnechnozemnaya fizika [Solar-Terrestrial Physics]. 2016, vol. 2, no. 4, pp. 118-125. DOI: $10.12737 / 24278$.

Picone J.M., Hedin A.E., Drob D.P., Aikin A.C. (GTD72000) NRLMSISE-00 Empirical model of the atmosphere: statistical comparisons and scientific issues. J. Geophys. Res. 2002, vol. 107, no. A12, p. 1469. DOI: 10.1029/2002JA009430.

Shchepkin L.A., Kushnarenko G.P., Freizon I.A., Kuznetsova G.M. The electron density connection with the thermospheric state in the middle ionosphere. Geomagnetizm $i$ aeronomiya [Geomagnetism and Aeronomy]. 1997, vol. 37, no. 5, pp. 106-113. (In Russian).

Solomon S.C., Woods T.N., Didkovsky L.V., Emmert J.T., Qian L. Anomalously low solar extreme ultraviolet irradiance and thermospheric density during solar minimum. Geophys. Res. Lett. 2010, vol. 37, L16103. DOI: 10.1029/2010GL044468.

Tobiska W.K., Eparvier F.G. EUV97: Improvements to EUV irradiance modeling in the soft X-rays and EUV. Solar Phys. 1998, vol. 147, no. 1, pp. 147-159.

Yakovleva O.E., Kushnarenko G.P., Kuznetsova G.M. The main gas components of the thermosphere $[\mathrm{O}] /\left[\mathrm{N}_{2}\right]$ and $\left[\mathrm{O}_{2}\right] /[\mathrm{O}]$ in the years of minimum solar activity (2007-2009) at the station Norilsk. Trudy Mezhdunarodnoi Baykalskoi molodezhnoi nauchnoi shkoly po fundamentalnoi fizike i konferentsii molodykh uchenykh "Vzaimodeystvie poley $i$ izlucheniya s veshchestvom" [Proceedings of Baikal Young Scientist's International School on Fundamental Physics and Young Scientist's Conference "Interaction of Fields and Radiation with Matter"]. Irkutsk, 2015, pp. 209-211. (In Russian).

URL: http://ckp-rf.ru/ckp/3056 (accessed at January 31, 2020).

URL: http://guvitimed.jhuapl.edu (accessed at January 31, 2020). 2020).

URL: http://wdc.kugi.kyoto-u.ac.jp (accessed at January 31,

How to cite this article

Yakovleva O.E., Kushnarenko G.P., Kuznetsova G.M. The atmosphere below $200 \mathrm{~km}$ over Norilsk at solar minimum and maximum. Solar-Terrestrial Physics. 2020. Vol. 6. Iss. 3. P. 86-89. DOI: 10.12737/stp-63202012. 